九州大学学術情報リポジトリ

Kyushu University Institutional Repository

\title{
Distinction of Grapholita molesta Busck and Grapholita dimorpha Komai larvae based on morphological feature of anal prolegs
}

Lee, Seung-Yeol

College of Agriculture and Life Sciences, Kyungpook National University

Choi, Kwang-Shik

College of Natural Sciences, Kyungpook National University

Back, Chang-Gi

National Institute of Horticultural and Herbal Science, Rural Development Administration

Choi, Kyung-Hee

National Institute of Horticultural and Herbal Science, Rural Development Administration 他

https://doi.org/10.5109/1526340

出版情報: 九州大学大学院農学研究院紀要. 60 (2)，pp.291-295，2015-09-18. Faculty of Agriculture, Kyushu University

バージョン：

権利関係 : 


\title{
Distinction of Grapholita molesta Busck and Grapholita dimorpha Komai larvae based on morphological feature of anal prolegs
}

\author{
Seung-Yeol LEE ${ }^{1}$, Kwang-Shik CHOI ${ }^{2}$, Chang-Gi BACK ${ }^{3}$, Kyung-Hee $\mathrm{CHOI}^{3}$, \\ In-Kyu KANG ${ }^{1}$, Hee-Young JUNG ${ }^{1 *}$ and Shoji OHGA*
}

\author{
Laboratory of Forest Resources Management, Division of Forest Environmental Sciences, \\ Department of Agro-environmental Sciences, Faculty of Agriculture, \\ Kyushu University, Sasaguri, Fukuoka 811-2415, Japan \\ (Received April 14, 2015 and accepted May 19, 2015)
}

\begin{abstract}
Larvae of Grapholita molesta Busck and Grapholita dimorpha Komai, which are major moth pests that affect apples in Korea, are very difficult to identify because of their morphological similarities. In this study, we investigated how to distinguish the larvae of these two species by using specific morphological features. Between 2013 and 2014, a total of 84 specimens were collected from apples suspected of infestation in Gunwi-gun and Cheongsong-gun, Gyeongsangbuk-do, Korea, and they were observed using a stereo microscope, optical microscope, and scanning electron microscope. We found that the number of anal proleg crochets of the two species was different. PCR-RFLP results for the two species showed that G. molesta and $G$. dimorpha have 18-28 and 12-17 anal proleg crochets, respectively. Our findings suggest that the number of anal proleg crochets could be an excellent morphological character that could be used to identify the larvae of the two species without the need for any further experiments.
\end{abstract}

Key words: Grapholita molesta, Grapholita dimorpha, Morphological difference, Number of crochets, PCR-RFLP

\section{INTRODUCTION}

The major insect pests found in apple orchards belong to the order Lepidoptera, for example, Carposina sasakii Matsumura belongs to the family Carposinidae and Grapholita molesta Busck and Grapholita dimorpha Komai belong to the family Tortricidae. Grapholita molesta is distributed worldwide and appears to favor drupe and pome fruits (Il'ichev et al., 2003; Natale et al., 2003; Kovanci et al., 2004). Grapholita dimorpha has hosts similar to those of $G$. molesta (Rothschild and Vicker, 1991), and its distribution is limited to mainly Northeast Asia, including Korea, Japan, China and Russia (Park and Kim, 1986; Komai, 1999; Yan et al., 1999; Beljaev and Ponomarenko, 2005). In Korea, G. dimorpha was reported in apple orchards in 2009 (Choi et al., 2009), also, it has been reported in pear, peach, and plum orchards (Jung et al., 2012; Ahn et al., 2013).

Choi et al. (2009) reported that $G$. molesta and $G$. dimorpha emerge 4 times a year, which is also similar to the periods of adult emergence; however, the population density of $G$. dimorpha tends to increase after July. Choi et al. (2008) indicated that G. molesta has infested more apples than C. sasakii since 1997; however, it was suggested that $G$. dimorpha might have been mistakenly identified as $G$. molesta (Choi et al., 2009). Because larvae of both $G$. molesta and $G$. dimorpha infest apples,

${ }^{1}$ College of Agriculture and Life Sciences, Kyungpook National University, Daegu 702-701, Korea

${ }^{2}$ College of Natural Sciences, Kyungpook National University, Daegu 702-701, Korea

National Institute of Horticultural and Herbal Science, Rural Development Administration, Suwon 440-760, Korea

* Corresponding author (E-mail: ohga@forest.kyushu-u.ac.jp, heeyoung@knu.ac.kr) it is very important to accurate identify them to better understand the situation and use effective control measures. However, it is impossible to identify the larvae of these two species on the basis of morphology, even though the adults of these species can be differentiated on the basis of wing width and patterns of the male hind wings (Komai, 1979).

Currently, species-specific polymerase chain reaction (PCR) primers and PCR-restriction fragment length polymorphism (RFLP) have been mainly used to identify G. molesta and G. dimorpha (Hada and Sekine, 2011; Jung et al., 2013; Jung et al., 2012; Ahn et al., 2013). However, morphological keys for the larvae of these two species are not available. In a recent study (Lee et al., 2013), G. molesta and C. sasakii larvae collected from apple orchards were identified using specific morphological features. Therefore, we investigated specific morphological differences between the larvae of $G$. molesta and G. dimorpha to identify them effectively.

\section{MATERIALS AND METHODS}

\section{Sample collection}

Between July and October in 2013 and 2014, larvae were collected from approximately 200 apples suspected of infestation in apple orchards in Gunwi-gun and Cheongsong-gun, Gyeongsangbuk-do, Korea. After the fruits were cut, larvae greater than $10 \mathrm{~mm}$ in length were collected. The specimens were used after they were rinsed 2 to 3 times in distilled water to remove debris.

\section{Species Identification}

After the larvae were prepared for microscopy by using ethyl acetate to ensure that the larvae were stationary (Steiner et al., 2010), arrangement of adfrontal setae 
and other morphological features were observed using a stereo microscope (DIMIS-M, Siwon Optical Technology Co., Ltd., Anyang, Korea) and optical microscope (Olympus BX-50, Japan). Initially, the specimens were identified morphologically to separate the larvae of $C$. sasakii and $G$. molesta by using the keys given by Lee et al. (2013). After morphological identification, only larvae belonging to the family Tortricidae were used for the study.

\section{Microscopic observation}

Arrangement of adfrontal setae, characters of the head and tail, and the number of anal proleg crochets were observed using a stereo microscope and optical microscope. Also, the width of head capsules were measured to check the each of larval instar stage. Six specimens showed morphological differences, and they were prepared and examined using a scanning electron microscope (SEM; magnification, 350×; S-3500N, Hitachi, Japan), according to the method described by Moon et al. (2009).

\section{Identification of G. molesta and G. dimorpha lar- vae by using PCR-RFLP}

After morphological examination, the specimens were identified using PCR-RFLP (Jung et al., 2013). Initially, genomic DNA samples were extracted using the cetyl trimethyl ammonium bromide method (Martinelli et al., 2007). A partial sequence of the NADH dehydrogenase 4 region was amplified using ND4-J-89441/ND4-RP primers (Simon et al., 1994). A total volume of $20 \mu \mathrm{L}$ for each reaction contained $0.5 \mu \mathrm{L}$ of the genomic DNA, $2 \mu \mathrm{L}$ of $10 \times$ Taq buffer, $1 \mu \mathrm{L}$ of $10 \mathrm{mM}$ dNTP, $10 \mathrm{pM}$ of each primer, and $0.2 \mu \mathrm{L}$ of Taq DNA polymerase (Solgent, Daejeon, Korea). PCR cycling conditions were as follows: a $2-\min 94^{\circ} \mathrm{C}$ denaturation step, followed by 35 cycles at $94^{\circ} \mathrm{C}$ for $60 \mathrm{~s}, 45^{\circ} \mathrm{C}$ for $45 \mathrm{~s}$, and $72^{\circ} \mathrm{C}$ for $90 \mathrm{~s}$; there was a final extension step at $72^{\circ} \mathrm{C}$ for $10 \mathrm{~min}$ (Jung et al., 2013). PCR product was electrophoresed through a $1 \%$ agarose gel, which was stained with ethidium bromide, and observed under ultraviolet light by using a UV illuminator. After PCR, 0.2 U of Swa I (5'-ATTT^AAAT-3'; Takara, Japan) was added to the PCR products, and digestion was performed at $30^{\circ} \mathrm{C}$ for $2 \mathrm{~h}$. Digested PCR products was electrophoresed through a 1\% agarose gel, stained with ethidium bromide, observed under ultraviolet light by using a UV illuminator.

\section{RESULTS AND DISCUSSION}

A total of 116 larvae were observed the size of the prothorax spiracles, number of subventral setae next to the proleg, and arrangement of the 8th abdominal segment using the method described by Lee et al. (2013). As the results, 32 and 84 larvae were identical to that of larvae that belong to the families Carposinidae and Tortricidae, respectively (Data not shown). Among the classified Tortricidae larvae, we observed various characteristics such as head shape and width, arrangement of subventral setae, anal comb and number of anal pro- leg crochets using stereo and optical microscope. All the examined Tortricidae larvae were identified using PCRRFLP method (Jung et al., 2013). PCR-RFLP results revealed that 13 of the 84 larvae identified as belonging to the family Tortricidae were $G$. dimorpha, and the other 71 larvae were G. molesta (Fig. 1). Based on PCRRFLP results, we compared each of morphological characteristics that observed using stereo and optical micro-

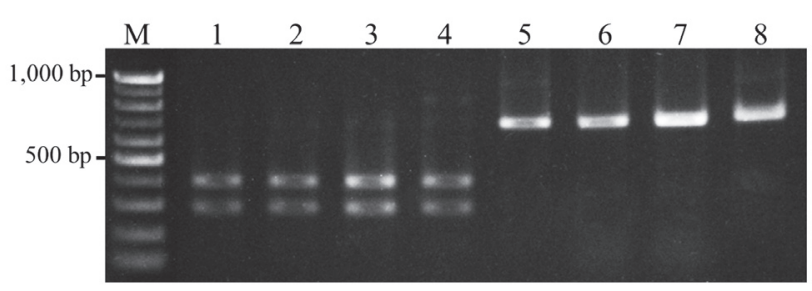

Fig. 1. Agarose gel (1\%) stained with ethidium bromide and showing the amplicons after PCR-RFLP. M: 100-bp DNA ladder, 1-4 lanes: $G$. dimorpha (390 bp and $290 \mathrm{bp),5-8}$ lanes: G. molesta (690 bp).

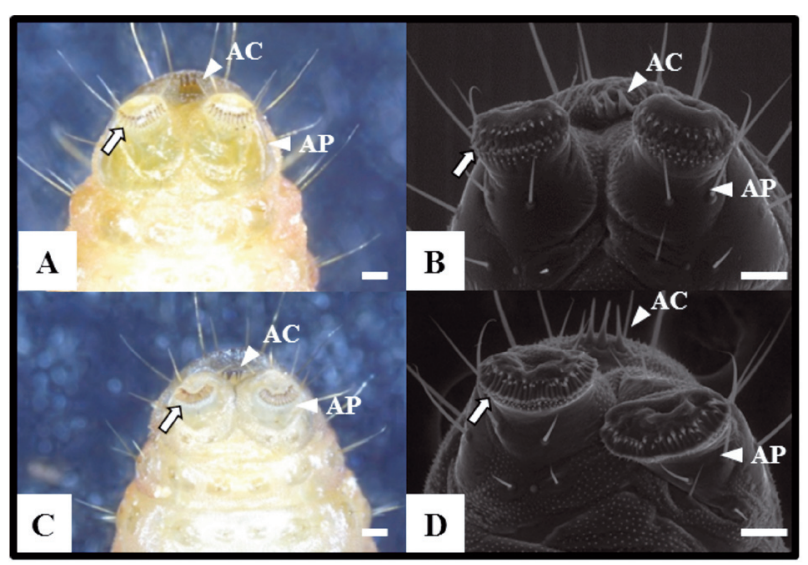

Fig. 2. Observed shape of anal proleg crochets from G. molesta and $G$. dimorpha larvae by using a stereo microscope and scanning electron microscope. A, B: Grapholita dimorpha. C, D: Grapholita molesta. AC: Anal comb, AP: Anal proleg, Arrow: Crochets. Scale bar $=100 \mu \mathrm{m}$.

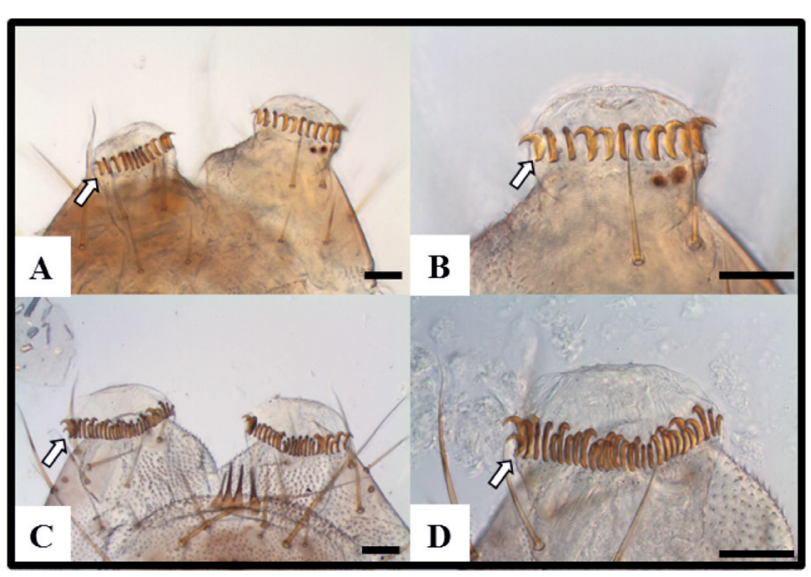

Fig. 3. Observed shape of the anal proleg crochets from $G$. molesta and $G$. dimorpha larvae by using an optical microscope. A, B: Grapholita dimorpha. C, D: Grapholita molesta. Arrow: Crochets. Scale bar $=100 \mu \mathrm{m}$. 
scope. Although there were no differences in head shape, arrangement of subventral setae, and presence of an anal comb (data not shown), larvae of the two species showed different numbers of anal proleg crochets when observed using a stereo microscope and SEM (Fig. 2, Table 1). Also, number of crochets of two anal legs; both side showed same number of crochets (Data not shown). Observation using an optical microscope confirmed that

Table 1. Identification of larvae belonging to the family Tortricidae and their number of anal proleg crochets

\begin{tabular}{|c|c|c|c|c|c|}
\hline Name & Identification Results & $\begin{array}{l}\text { Number of anal } \\
\text { proleg crochets }\end{array}$ & Name & Identification Results & $\begin{array}{l}\text { Number of anal } \\
\text { proleg crochets }\end{array}$ \\
\hline Tortri-1 & G. dimorpha & 13 & Tortri-43 & G. molesta & 23 \\
\hline Tortri-2 & G. dimorpha & 13 & Tortri-44 & G. molesta & 19 \\
\hline Tortri-3 & G. dimorpha & 17 & Tortri-45 & G. molesta & 24 \\
\hline Tortri-4 & G. dimorpha & 13 & Tortri-46 & G. molesta & 19 \\
\hline Tortri-5 & G. dimorpha & 12 & Tortri-47 & G. molesta & 20 \\
\hline Tortri-6 & G. dimorpha & 13 & Tortri-48 & G. molesta & 20 \\
\hline Tortri-7 & G. dimorpha & 13 & Tortri-49 & G. molesta & 18 \\
\hline Tortri-8 & G. dimorpha & 15 & Tortri-50 & G. molesta & 20 \\
\hline Tortri-9 & G. dimorpha & 13 & Tortri-51 & G. molesta & 25 \\
\hline Tortri-10 & G. dimorpha & 16 & Tortri-52 & G. molesta & 22 \\
\hline Tortri-11 & G. dimorpha & 15 & Tortri-53 & G. molesta & 20 \\
\hline Tortri-12 & G. dimorpha & 13 & Tortri-54 & G. molesta & 19 \\
\hline Tortri-13 & G. dimorpha & 16 & Tortri-55 & G. molesta & 18 \\
\hline Tortri-14 & G. molesta & 20 & Tortri-56 & G. molesta & 20 \\
\hline Tortri-15 & G. molesta & 20 & Tortri-57 & G. molesta & 22 \\
\hline Tortri-16 & G. molesta & 20 & Tortri-58 & G. molesta & 25 \\
\hline Tortri-17 & G. molesta & 25 & Tortri-59 & G. molesta & 20 \\
\hline Tortri-18 & G. molesta & 18 & Tortri-60 & G. molesta & 23 \\
\hline Tortri-19 & G. molesta & 21 & Tortri-61 & G. molesta & 28 \\
\hline Tortri-20 & G. molesta & 23 & Tortri-62 & G. molesta & 27 \\
\hline Tortri-21 & G. molesta & 22 & Tortri-63 & G. molesta & 24 \\
\hline Tortri-22 & G. molesta & 20 & Tortri-64 & G. molesta & 21 \\
\hline Tortri-23 & G. molesta & 20 & Tortri-65 & G. molesta & 18 \\
\hline Tortri-24 & G. molesta & 21 & Tortri-66 & G. molesta & 21 \\
\hline Tortri-25 & G. molesta & 22 & Tortri-67 & G. molesta & 22 \\
\hline Tortri-26 & G. molesta & 21 & Tortri-68 & G. molesta & 22 \\
\hline Tortri-27 & G. molesta & 25 & Tortri-69 & G. molesta & 22 \\
\hline Tortri-28 & G. molesta & 22 & Tortri-70 & G. molesta & 20 \\
\hline Tortri-29 & G. molesta & 24 & Tortri-71 & G. molesta & 22 \\
\hline Tortri-30 & G. molesta & 24 & Tortri-72 & G. molesta & 18 \\
\hline Tortri-31 & G. molesta & 26 & Tortri-73 & G. molesta & 19 \\
\hline Tortri-32 & G. molesta & 21 & Tortri-74 & G. molesta & 18 \\
\hline Tortri-33 & G. molesta & 23 & Tortri-75 & G. molesta & 19 \\
\hline Tortri-34 & G. molesta & 24 & Tortri-76 & G. molesta & 19 \\
\hline Tortri-35 & G. molesta & 23 & Tortri-77 & G. molesta & 18 \\
\hline Tortri-36 & G. molesta & 19 & Tortri-78 & G. molesta & 21 \\
\hline Tortri-37 & G. molesta & 24 & Tortri-79 & G. molesta & 23 \\
\hline Tortri-38 & G. molesta & 24 & Tortri-80 & G. molesta & 20 \\
\hline Tortri-39 & G. molesta & 18 & Tortri-81 & G. molesta & 20 \\
\hline Tortri-40 & G. molesta & 24 & Tortri-82 & G. molesta & 19 \\
\hline Tortri-41 & G. molesta & 23 & Tortri-83 & G. molesta & 23 \\
\hline Tortri-42 & G. molesta & 24 & Tortri-84 & G. molesta & 18 \\
\hline
\end{tabular}




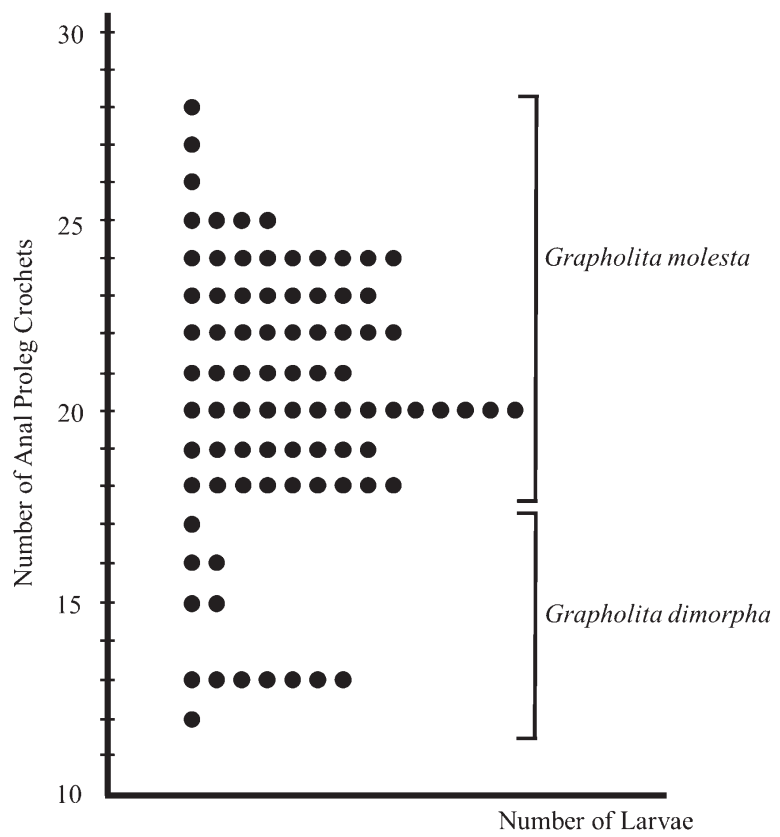

Fig. 4. Observed number of anal proleg crochets in G. molesta and $G$. dimorpha larvae.

the shape of the crochets of larvae of both species was semi-circular and uniordinal or biordinal (Fig. 3). Microscopic analysis showed that the number ranges of the anal proleg crochets for larvae of the two species were different (Table 1). Furthermore, width of the head capsule of examined larvae were shown as 1072.7 \pm $143.2 \mu \mathrm{m}$ (Data not shown). This range was almost matched with head capsule width of $5^{\text {th }}$ instar of $G$. molesta (Yokoyama, 1987). Although all the examined larvae were equally $5^{\text {th }}$ mature stage, the number ranges for the anal proleg crochets were 12-17 for G. dimorpha and 18-28 for G. molesta (Fig. 4). On the basis of the results of microscopic observation and molecular identification, different numbers of anal proleg crochets between $G$. molesta and $G$. dimorpha larvae can be considered a good diagnostic criterion for the identification of the two species.

The shape of the crochets on the prolegs of larvae is a species-specific morphological character (Nasu et al., 2004; Matthews et al., 1994). Moreover, this feature is used for the identification of larval species (Brown and Komai, 2008; Wearing et al., 2001; Rentel, 2013). Nasu et al. (2004) reported that the number of anal proleg crochets in Copromorpha kijimuna (Copromorphidae) larvae was 11 or 12 . The numbers of anal proleg crochets in Exelastis cervinicolor (Platyptilinae) and Exelastis pumilio larvae were 4 and 11, respectively (Matthews et al., 1994). Furthermore, cherry tree borer (Synanthedon bicingulata Staudinger, Lepidoptera: Sessidae) larvae, a major fruit pest in Korea, have approximately 11 anal proleg crochets (Lee et al., 2004). Cydia pomonella (Lepidoptera; Tortricidae), a pest of sweet cherry, has 25-35 anal proleg crochets, whereas a closely related species, Cydia splendana, has 15-20 anal proleg crochets (Wearing et al., 2001). Brown and Komai (2008) identified specimens as C. splendana if they had less than 18 anal proleg crochets and as Cydia fagiglandana if they had more than 18 anal proleg crochets, after taking body color and distance of the proleg on the 9th abdominal segment into account. Rentel (2013) reported that the number of anal proleg crochets was different for 6 agricultural pest species belonging to Tortricidae in South Africa: Thaumatotibia leucotreta (False codling moth), C. pomonella (Codling moth), G. molesta (Oriental fruit moth), Thaumatotibia batrachopa (Macadamia nut borer), Cryptophlebia peltastica (Litchi moth), and Epichoristodes acerbella (Pear leaf roller/Carnation worm). He also reported that the number of anal proleg crochets in $G$. molesta larvae was $19-25$, similar to the findings of this study.

To date, the morphologies of $G$. molesta and $G$. dimorpha larvae, which are major apple pests in Korea, have not been differentiated (Komai, 1979). However, we found differences in the number of anal proleg crochets between $G$. molesta and $G$. dimorpha larvae by using a stereo microscope, optical microscope, and SEM. These results were confirmed using PCR-RFLP. Thus, the number of anal proleg crochets would be a good morphological criterion for the identification of $G$. molesta and $G$. dimorpha larvae. Further investigation should be performed by collecting the two species from different localities and hosts such as plum, pear, and peach.

\section{REFERENCES}

Ahn, S. J., K. H. Choi, T. J. Kang, H. H. Kim, D. H. Kim, M. R. Cho and C. Y. Yang 2013 Molecular diagnosis of Grapholita molesta and Grapholita dimorpha and their different occurrence in peach and plum. Korean J. Appl. Entomol., 52: 365-370

Beljaev, E. A. and M. G. Ponomarenko 2005 New lepidopterological finds (Lepidoptera: Gelechiidae, Tortricidae, Geometridae) in south of Russian Far East. Far East. Entomol., 155: 1-11

Brown, J. W. and F. Komai 2008 Key to larvae of Castanea-feeding Olethreutinae frequently intercepted at U.S. ports-of-entry (Lepidoptera: Tortricidae). Trop. Lepidop., 18: 2-4

Choi, K. H., D. H. Lee, B. K. Byun and F. Mochizuki 2009 Occurrence of Grapholita dimorpha Komai (Lepidoptera: Tortricidae), a new insect pest in apple orchards of Korea. Korean J. Appl. Entomol., 48: 417-421

Choi, K. H., S. W. Lee, D. H. Lee, D. A. Kim and S. K. Kim 2008 Recent occurrence status of two major fruits moths, oriental fruit moth and peach fruit moth in apple orchards. Korean J. Appl. Entomol., 47: 17-22

Hada, H. and K. T. Sekine 2011 A diagnostic multiplex polymerase chain reaction method to identify Japanese internal apple-feeding Lepidopteran pests: Grapholita molesta, Grapholita dimorpha (Lepidoptera: Tortricidae), and Carposina sasakii (Lepidoptera: Carposinidae). Appl. Entomol. Zool., 46: 287291

Il'ichev, A. L., D. G. Williams and A. Drago 2003 Distribution of the oriental fruit moth Grapholita molesta Busck (Lep., Tortricidae) infestation on newly planted peaches before and during 2 years of mating disruption. J. Appl. Entomol., 127: 348-353

Jung, C. R., J. J. Ahn, H. S. Eom, J. H. Seo and Y. Kim 2012 Occurrence of Grapholita dimorpha in Korean pear orchards and cross-trapping of its sibling species, Grapholita molesta, to a pheromone lure. Korean J. Appl. Entomol., 51: 479-484

Jung, C. R. and Y. Kim 2013 Different types of fruit damages of three internal apple feeders diagnosed with mitochondrial molecular markers. J. Asia-Pacific Entomol., 16: 189-197

Komai, F. 1979 A new species of the genus Grapholita treitschke 
form Japan allied to the oriental fruit moth, Grapholita molesta (Busck) (Lepidoptera: Tortricidae). Appl. Entomol. Zool., 14: $133-136$

Komai, F. 1999 A taxonomic review of the genus Grapholita and allied genera (Lepidoptera: Tortricidae) in the Palaearctic region. Entomol. Scand. Suppl., 55: 1-226

Kovanci, O. B., J. F. Walgenbach and G. G. Kennedy 2004 Evaluation of extended-season mating disruption of the oriental fruit moth Grapholita molesta (Busck) (Lep., Tortricidae) in apples. J. Appl. Entomol., 128: 664-669

Lee, C. M., Y. S. Bae and Y. Arita 2004 Morphological description of Synanthedon bicingulata (Staudinger, 1887) in life stages (Lepidoptera, Sesiidae). J. Asia-Pacific Entomol., 7: 177-185

Lee, S. Y., K. S. Choi, K. H. Choi, T. M. Yoon and H. Y. Jung 2013 Morphological differences between larvae of the oriental fruit moth (Grapholita molesta Busck) and the peach fruit moth (Carposina sasakii Matsumura) in Korea. Appl. Microscopy, 43: $21-26$

Martinelli, S., P. L. Clark, M. I. Zucchi, M. C. Silva-Filho, J. E. Foster and C. Omoto 2007 Genetic structure and molecular variability of Spodoptera frugiperda (Lepidoptera: Noctuidae) collected in maize and cotton fields in Brazil. B. Entomol. Res., 97: $225-231$

Matthews, D. L., D. H. Habeck and B. Landry 1994 Immature stages of Exelastis plume moths in Florida (Lepidoptera: Pterophoridae: Platyptiliinae). Trop. Lepidop., 5: 43-53

Moon, M. J. and J. G. Park 2009 Fine structural analysis of the attachment devices in the jumping spider Plexippus setipes. Korean J. Microscopy, 39: 149-156

Nasu, Y., T. Saito and F. Komai 2004 Discovery of the previously unrecorded family Copromorphidae Meyrick (Lepidoptera) in
Japan, with description of a new species and autapomorphies for the family. Entomol. Sci., 7: 73-83

Natale, D., L. Mattiacci, A. Hern, E. Pasqualini and S. Dorn 2003 Response of female Cydia molesta (Lepidoptera: Tortricidae) to plant derived volatiles. Bull. Entomol. Res., 93: 335-342

Park, K. T. and J. M. Kim 1986 Moths collected in the northern part of civilian control line neighbouring D.M.Z. Korean J. Plant Prot., 25: 77-83

Rentel, M. 2013 Morphology and taxonomy of tortricid moth pests attacking fruit crops in South Africa. Master Degree Thesis. Stellenbosch University, Matieland, South Africa.

Rothschild, G. H. L. and R. A. Vickers 1991 Biology, ecology and control of the oriental fruit moth, in: van der Geest, L. P. S. and H. H. Evenhuis (Eds.), Tortricid pests, their biology, natural enemies and control. Elsevier, Amsterdam, pp. 389-412

Simon, C., F. Frati, A. Beckenbach, B. Crespi, H. Liu and P. Flook 1994 Evolution, weighting, and phylogenetic utility of mitochondrial gene sequences and a compilation of conserved polymerase chain reaction primers. Ann. Entomol. Soc. Am. 87: $651-701$

Wearing, C. H., J. D. Hansen, C. Whyte, C. E. Miller and J. Brown 2001 The potential for spread of codling moth (Lepidoptera: Tortricidae) via commercial sweet cherry fruit: a critical review and risk assessment. Crop Protect., 20: 465-488

Yan, S., Y. Liu and M. Li 1999 Grapholita dimorpha - a new record pest damage fruit trees of China. For. Pest Dis., 18 $15-16$

Yokoyama, V. Y., T. M. Miller and J. M. Harvey 1987 Development of oriental fruit moth (Lepidoptera: Tortricidae) on a laboratory diet. J. Econ. Entomol., 80: 272-276 